\title{
Sustainability in Marketing, Academic Perspectives: An Abstract
}

\author{
Joya A. Kemper, Paul W. Ballantine, and C. Michael Hall
}

\begin{abstract}
Sustainability in marketing has gained some traction over the years, evidenced in part by growing interest in past and upcoming special issues on the topic in numerous marketing journals. However, integrating such contested topics as sustainability and marketing suggests multiple ways in which sustainability can be addressed in marketing. Consequently, interviews were conducted with sustainability-focused marketing academics from around the world to understand how sustainability can be integrated within the marketing and really come to understand what 'sustainability marketing' as a concept entails.
\end{abstract}

\footnotetext{
J.A. Kemper $(\triangle) \cdot$ P.W. Ballantine $\bullet$ C. Michael Hall University of Canterbury, Christchurch, New Zealand e-mail: joya.kemper@pg.canterbury.ac.nz; paul.ballantine@ canterbury.ac.nz; michael.hall@ canterbury.ac.nz
} 